\title{
Subsurface Chemistry of the Imbrium Basin Inferred from Clementine UVVIS Spectroscopy
}

\author{
Hisashi Otake ${ }^{1}$ and Hitoshi Mizutani ${ }^{2,3}$ \\ ${ }^{1}$ SELENE project team, ISAS, JAXA, Sengen, Tsukuba, Ibaraki 305-8505, Japan \\ ${ }^{2}$ Division of Planetary Science, ISAS, JAXA, Yoshinodai, Sagamihara, Kanagawa 229-8510, Japan \\ ${ }^{3}$ Newton Press Inc., Nishi-Shinjuku, Shinjuku-ku, Tokyo 163-0207, Japan
}

(Received March 18, 2005; Revised May 26, 2006; Accepted June 9, 2006; Online published December 25, 2006)

\begin{abstract}
Since ejecta around an impact crater is excavated from a depth, its mineralogy and chemistry will provide us with information on the composition of the pre-impact subsurface. The depth from which crater ejecta were excavated was determined from laboratory experiments, field studies, and a simplified quantitative model (Zmodel and the scaling law of ejection velocity). Based on the results of these studies, it is believed that surface material of an ejecta blanket between 1.1 and 1.5 radii from the crater was excavated from a depth of 0.13 to 0.15 radii. The following results were obtained from combining the surface and subsurface basalt distributions with crater-counting ages for the mare basalt, we obtained the following results: (1) The averages of $\mathrm{TiO}_{2}$ and $\mathrm{FeO}$ increased with time from the Imbrian to the Eratosthenian periods, which is represented by a continuous trend curve on the $\mathrm{TiO}_{2}-\mathrm{FeO}$ graph: (2) volcanic activities in Mare Imbrium drastically decreased and basalts changed from a low-Ti to high-Ti content around the transition of the Imbrian to Eratosthenian period: (3) basalts with less than $3 \mathrm{wt} \% \mathrm{TiO}_{2}$ erupted in succession mainly in the Imbrian period.
\end{abstract}

Key words: Imbrium basin, subsurface, ejecta, age, volcanism.

\section{Introduction}

Lunar mare basalt deposits cover $17 \%$ of the lunar surface and have a total volume estimated at $10^{7} \mathrm{~km}^{3}$, which is less than $1 \%$ of the total volume of the crust (Head, 1975). Despite its low abundance, analysis of mare basalt derived from the mantle is important, since it provides mineral and chemical information about the lunar interior (Neal and Taylor, 1992) and gives as well as constraints on the thermal evolution of the Moon.

Basaltic samples returned from the various maria on the Moon have been classified into several different groups based on $\mathrm{TiO}_{2}$ content. The ages of Ti-rich basalts (Apollo 11 and 17) are 3.6 to $3.9 \mathrm{Ga}$ while those of the less-Tirich basalts (Apollo 12 and 15) are 3.2 to 3.4 Ga.Based on an assimilation of chemical, mineral, isotopic, and other data collected on these basalts, several models for mare basalt generation have been proposed (Green and Ringwood, 1973; Taylor and Jakes, 1974; O'Hara et al., 1975; Kesson, 1975; Hubbard and Minear, 1975; Ringwood, 1975; Shih and Schonfeld, 1976; Ringwood and Kesson, 1976; Binder, 1982). These models have a basis in the fact that the ages of high-Ti basalt (3.6-3.9 Ga) are older than those of low-Ti basalts (3.2-3.4 Ga).

aHowever, recent studies using the global titanium (Ti) distribution map from remote-sensing data have shown that there is no systematic variation in $\mathrm{Ti}$ abundances with

Copyright (c) The Society of Geomagnetism and Earth, Planetary and Space Sciences (SGEPSS); The Seismological Society of Japan; The Volcanological Society of Japan; The Geodetic Society of Japan; The Japanese Society for Planetary Sciences; TERRAPUB. time (Hiesinger et al., 2001). Contrary to earlier studies, Hiesinger et al. (2000a) demonstrated that younger basalts show a tendency to be more Ti-rich than older basalts in Oceanus Procellarum. Because the age and duration of basalt eruption depend on the age of basin formation, the thermal and chemical history of the basalts may depend on the location. Consequently we have analyzed the basalts and their variation in chemical composition and eruption volume with time in Mare Imbrium. Within the context of the results, wi will then discuss the genesis and thermal conditions of mare basalt under Imbrium basin.

Imbrium is the Moon's largest and well preserved basin. It has a rim-to-rim diameter of $675 \mathrm{~km}$ (Wilhelms, 1987), and almost the whole inside of the basin is covered with basalt lava flows. Volcanic activity in Imbrium Basin lasted several hundred million years from the Imbrian (3.8 and3.3 Ga) to the Eratosthenian period $(3.3-2.3 \mathrm{Ga})$, and the basalts have a wide range of $\mathrm{TiO}_{2}(0.5-11 \mathrm{wt} \%)$, including both Ti-rich and Ti-poor basalt. Therefore, the relationship between chemical composition, eruption volume and its temporal history will provide important information to our better understanding of the lunar geological history.

Spectral images of the entire lunar surface were obtained with high spatial resolution by the Clementine mission (Nozette et al., 1994), and this images have made it possible to investigate small geological features such as lava flows and crater ejecta. The first global map of thorium distribution was produced using gamma-ray spectrum data obtained by the Lunar Prospector mission (Lawrence et al., 2000). In this study, we investigated the presence of basalt, 


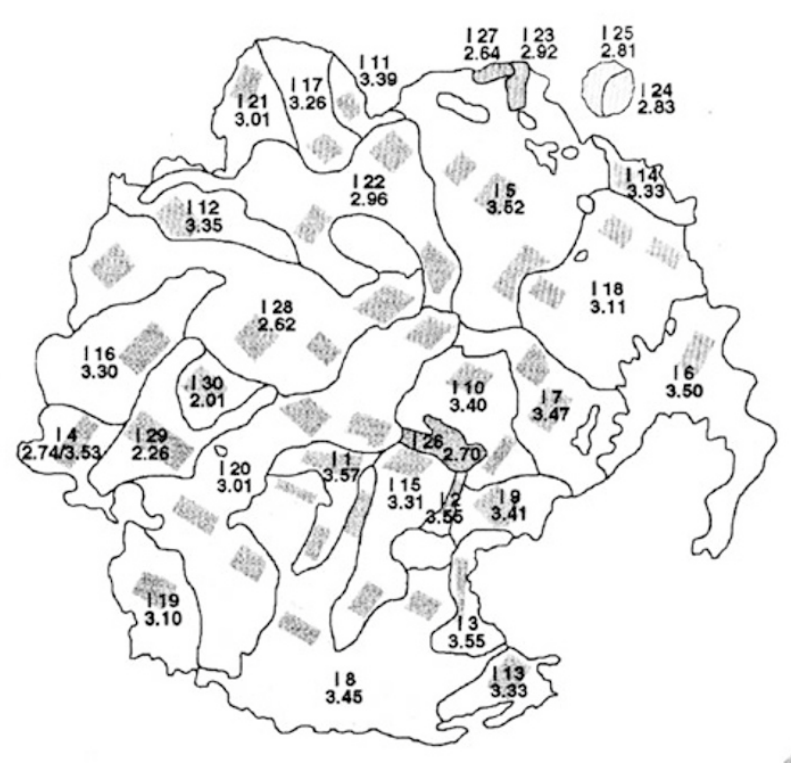

Fig. 1. Spatial distribution of ages in Mare Imbrium (Hiesinger et al., 2000b). The unit number (upper number) and age (lower number) are shown in billion years in each domain. Crater size-frequency distribution measurements were performed for the highlighted dark-gray areas.

both on the surface and underground using the compositional data of ejecta from various size craters.

\section{Data Used in This Study \\ 2.1 Relative ages of flow units}

Hiesinger et al. (2000b) obtained the ages of surface units in Imbrian basin by applying the method of crater size-frequency distributions to multispectral Galileo Earth/Moon Encounter 2 imaging data in order to identify homogeneous areas. Morphological and/or albedo features were also taken into account, such as the three distinct latestage lava flows mapped with Apollo photographs by Schaber (1973).

As shown in Fig. 1, Hiesinger et al. dated 30 spectrally defined units between 2.01 and $3.57 \mathrm{Ga}$ that showed an extremely long period of volcanic activity in this basin. Western basalts showed a tendency to be slightly younger than eastern basalts. About $52 \%$ of all units in Mare Imbrium exhibit ages of 3.3-3.6 Ga, with all other units being younger than $3.3 \mathrm{Ga}$ but older than than $2.6 \mathrm{Ga}$ with the exception of units I29 (2.26 Ga) and I30 (2.01 Ga) (Hiesinger et al., $2000 \mathrm{~b})$. These researchers concluded that the largest number of basalts erupted in the period 3.3-3.6 Ga and that volcanism continued thereafter at a significantly lower intensity until $2.6 \mathrm{Ga}$.

In the study reported here, we subdivide the Imbrian and Eratosthenian periods into two periods each in accordance to Boyce and Dial (1975) and Boyce (1976) who determined relative age $\left(\mathrm{D}_{L}\right)$ : lower Imbrian $(\operatorname{Im} 1)$ and upper Imbrian (Im2) and lower Eratosthenian (Er1) and upper Eratosthenian $(\mathrm{Er} 2)$. The ages of those periods are defined as follows: Im1 (3.9-3.6 Ga), Im2 (3.6-3.3 Ga), Er1 (3.3-2.9 $\mathrm{Ga})$, and $\operatorname{Er} 2(2.9-2.3 \mathrm{Ga})$.

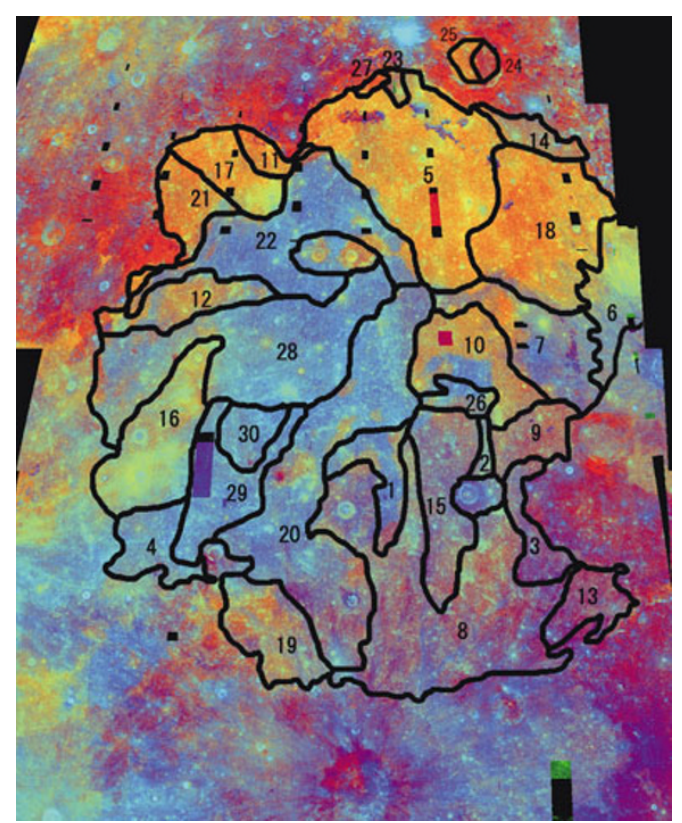

Fig. 2. False color composite of a ratioed image. This false color product consists of the color ratios 750/415 nm (red), 750/950 nm (green), and $415 / 750 \mathrm{~nm}$ (blue). The geologic units with numbers are defined by Hiesinger et al. (2000b).

\subsection{Clementine UVVIS camera images}

Spectral images of the entire Moon's surface were obtained at high spatial resolution by Clementine during its orbital mapping mission (Nozette et al., 1994). A digital image model (DIM) of the Moon with five spectral bands and with a spatial resolution of $100 \mathrm{~m} /$ pixel was produced from Clementine UVVIS data provided by the US Geological Survey Flagstaff (Eliason et al., 1999). This DIM was made with geometric control, radiometric calibration, photometric and phase normalization, and a destriping correction to match the first and the second month's orbit strips. Image cubes containing Mare Imbrium were extracted from the DIM for this study. The images were in a sinusoidal map centered on the meridian of $339^{\circ}$ degrees, at $200 \mathrm{~m} /$ pixel spatial resolution.

Figure 2 shows a band ratio image with color assignments of red $=750 / 415 \mathrm{~nm}$, green $=750 / 950 \mathrm{~nm}$, and blue $=415 / 750 \mathrm{~nm}$. Variations in the $1-\mu \mathrm{m}$ region add green tones for the larger 750/950-nm values that imply stronger $1-\mu \mathrm{m}$ absorptions. The number of each geologic unit defined by Hiesinger et al. (2000b) is also shown. The exposure of basalts of orange or yellow in the color code are distributed in the northern part of the basin (Units $21,17,11,5,18,10$, and 12). Basalts exposed in these areas indicates that the basalts have steep continuum slopes, i.e. a larger reduction of reflectance in the visible wavelength than that in the near-infrared wavelength, and that the basalts coded orange have weaker $1-\mu \mathrm{m}$ absorptions. This feature of the spectrum is thought to be caused by the presence of mafic minerals with less $\mathrm{Fe}^{2+}$ - in comparison to the basalts coded yellow-as a result of $\mathrm{Fe}^{2+}$ being reduced to $\mathrm{Fe}^{0}$ during the process of space weathering (Sasaki et al., 2001). The western basalts (Units 22, 28, 30, 29, 20, 1, and 4) have blue characteristics, indicating that these basalts 


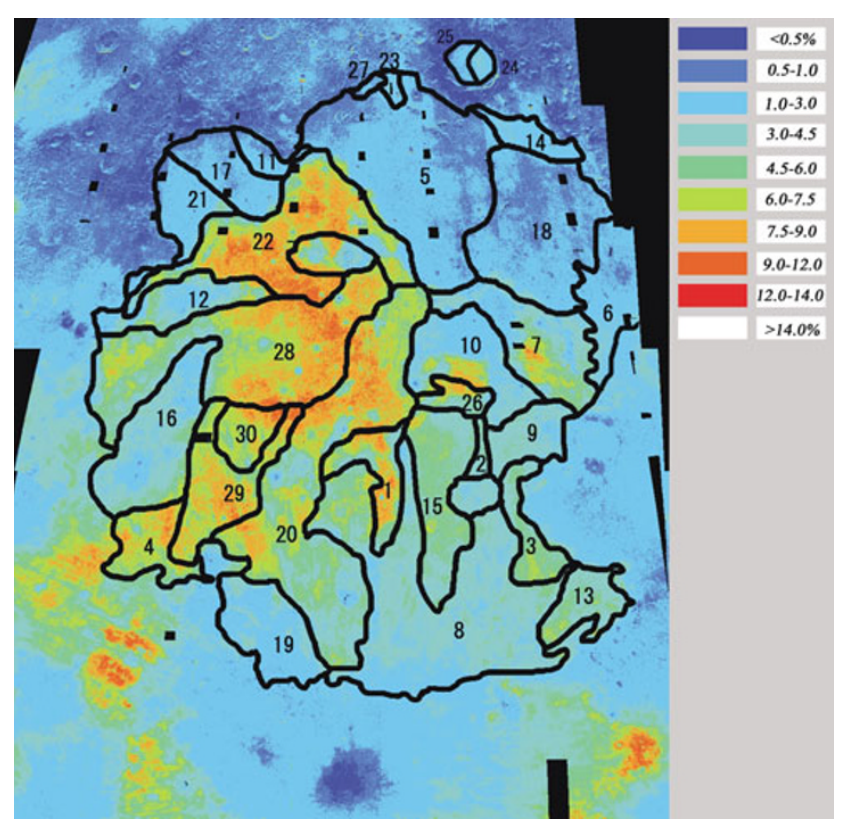

Fig. 3. $\mathrm{TiO}_{2}$ distribution map using the algorithm of Lucey et al. (2000a).

have gentle continuum slopes caused by higher contents of Ti or a smaller effect of space weathering than those in the yellow or orange basalts. Basalts distributed on the surface in Units $8,15,13,20,19$, and 3 are overlaid extensively by ejecta rays of highland red materials extending from the Copernicus crater. Thus these units belong to the Copernican age and must be carefully treated in order to derive information on Imbrian and Eratosthenian geology.

Lucey et al. (2000a) determined global $\mathrm{TiO}_{2}$ distribution of soils: using the algorithms for correcting the effects of space weathering on the spectral ratios. In Fig. 3 the distribution of $\mathrm{TiO}_{2}$ in Mare Imbrium is shown using the same algorithm as that developed by Lucey et al. (2000a). A comparison of Figs. 2 and 3 shows that the western Units 22, 28, 29, 30, 20, and 1 basalts have the highest $\mathrm{TiO}_{2}(6-$ $12 \mathrm{wt} \%$ ) in Mare Imbrium. On the other hand, the eastern Units 27, 23, 5, 14, 18, 6, 7, 10, 9, 2, 15 and 3 basalts, which are older than the western Units basalts (Hiesinger et al., 2000b), have a lower $\mathrm{TiO}_{2}$ content than those of the western basalts. Among the eastern Units, the Units 27, 23, $5,14,18,6$, and 10 in the northern part of the basin that are represented by orange or yellow in Fig. 2 have the lowest $\mathrm{TiO}_{2}$ content $(<3 \mathrm{wt} \%)$ in Mare Imbrium.

Neal and Taylor (1992) subdivided mare basalt samples returned by Apollo and Luna missions based on chemical composition with $\mathrm{TiO}_{2}$ being used as the primary criterion for classifying the basalts (classification at $1 \mathrm{wt} \%$ and 6 wt $\%$ which divided the basalts into very low-Ti (VLT), lowTi (LT), and high-Ti (HT) groups). In the present study, low-Ti basalts are further divided into LT1 (1-3 wt\%) and LT2 (3-6 wt\%).

A value called "Omat", the degree of space weathering (higher value means a lower degree of space weathering), was determined by Lucey et al. (2000b), and the distribution of Omat in Mare Imbrium is shown in Fig. 4. Basalts excavated and distributed around fresh craters have a higher

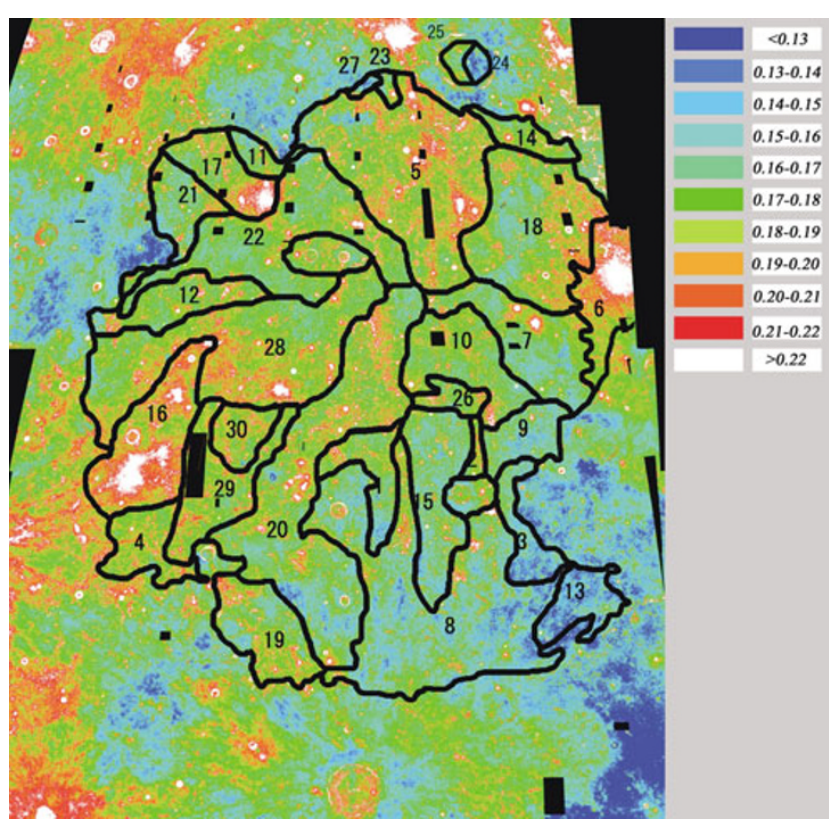

Fig. 4. Omat distribution map using the algorithm of Lucey et al. (2000b).

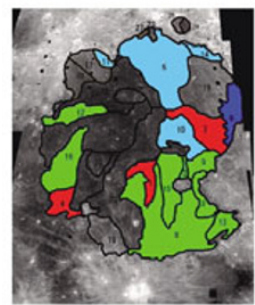

(a) $\operatorname{Im} 2$ period $(3.6-3.3 \mathrm{Ga})$

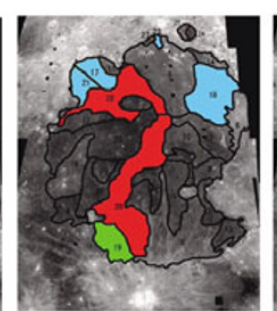

(b) Erl period $(3.3-2.9 \mathrm{Ga})$

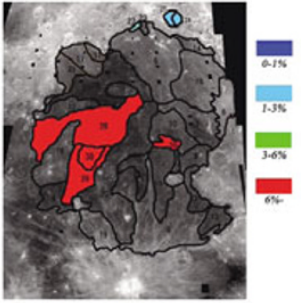

(c) Er2 period $(2.9 \mathrm{Ga}-)$
Fig. 5. Distribution and $\mathrm{TiO}_{2}$ content of the basalts on the surface: (a) Im2, (b) Er1, (c) Er2. Distribution map using the algorithm of Lucey et al. (2000a).

Omat (over 0.19) than other basalts. Ejecta rays of highland red materials extending from the Copernicus crater have lower Omat of less than 0.15 .

Figure 5 shows the temporal and areal $\mathrm{TiO}_{2}$ content in Imbrium basin, and Fig. 6 shows the surface area of basalt flow units as a function of age. If the thickness of each basaltic flow unit is the same, this diagram indicates the variations in volcanic history. The volcanic flux seems to have decreased to $50 \%$ or less in the Er1 and Er2 periods, as indicated by the decrease in the total area of basalts exposed. In the Im 2 period, LT2 basalts (green in the color code) amount to about $50 \%$ of all the basalts erupted in this period. LT1 basalts (blue in the color code) are the second most dominant type (about 30\%), and HT basalts (red in the color code) account for less than $10 \%$ of all basalts. VLT basalts (dark blue in the color code) erupted only in the Im 2 period. In contrast to the decreases of LT1, LT2 and VLT basalts with time, HT basalts increased, and their proportion exceeds $50 \%$ of all basalts erupted in the Er1 period and accounts for almost $100 \%$ of all basalts erupted in the Er2 period. Thus, volcanic activities in Mare Imbrium drastically decreased and $\mathrm{TiO}_{2}$ changed from LT2 to HT 


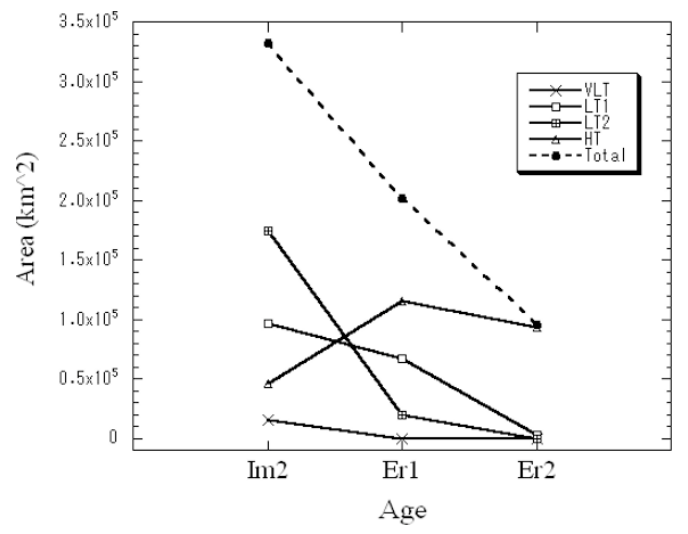

Fig. 6. Variation of the area of basalts on the ground. Total area of the basalts exposed decreases with time. LT2 basalts account for about 50\% of all $\operatorname{Im} 2$ basalts exposed on the ground, and this proportion decreases drastically from the $\operatorname{Im} 2$ to Er1 period. VLT basalts erupted only in the $\operatorname{Im} 2$ period. LT1 basalts decreased gradually from the $\operatorname{Im} 2$ to the $\operatorname{Er} 1$ period and drastically from the Er1 to the Er2 period. In contrast to the decrease in VLT, LT1 and LT2 basalts with time, HT basalts increased. The area of HT basalts amount to about $80 \%$ of those erupted in the Er2 period.

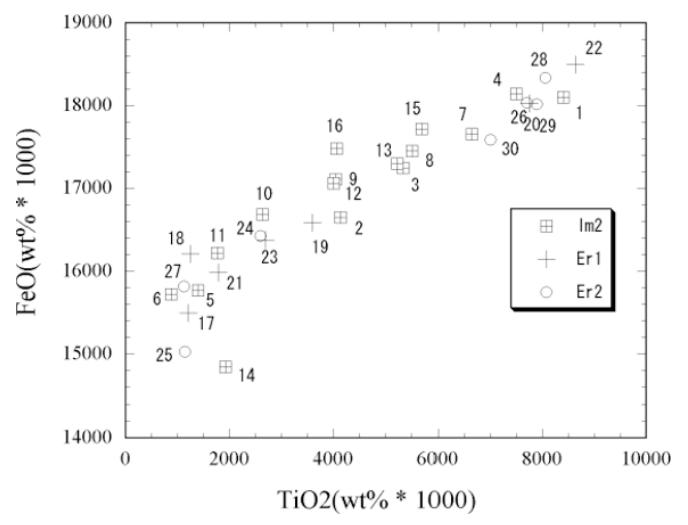

Fig. 7. Average $\mathrm{TiO}_{2}$ and $\mathrm{FeO}$ of the basalt in each geologic unit.

around the turn of the Imbrian to Eratosthenian period. A relatively small amount of the HT basalts erupted during the last stage of volcanic activity in Mare Imbrium.

In order to avoid contamination of the effect of ejecta material around craters (which is described in later sections in this paper), we sampled 332 points from all the units in Fig. 1 at an adequate distance from the craters, although fewer points were extracted from Units 8, 15, 19, and 20 since these units are overlaid by ejecta from the Copernicus Crater. The extracted points are shown with $\mathrm{TiO}_{2}$ content in Fig. 12(a). The $3 \times 3$ pixels were binned to represent the chemical composition of each point. Figure 7 depicts the positive correlation between $\mathrm{TiO}_{2}$ and $\mathrm{FeO}$ of each unit, which is the average of the contents of the points in each unit. All units are found to be plotted in nearly one positive $\mathrm{TiO}_{2}-\mathrm{FeO}$ correlation, regardless of the eruption period and volume.

\section{Method of Estimating the Subsurface Structure}

We now present techniques for determining the subsurface structure of maria using the ejecta of impact craters that excavate underlying material. Figure 8 shows three typ-

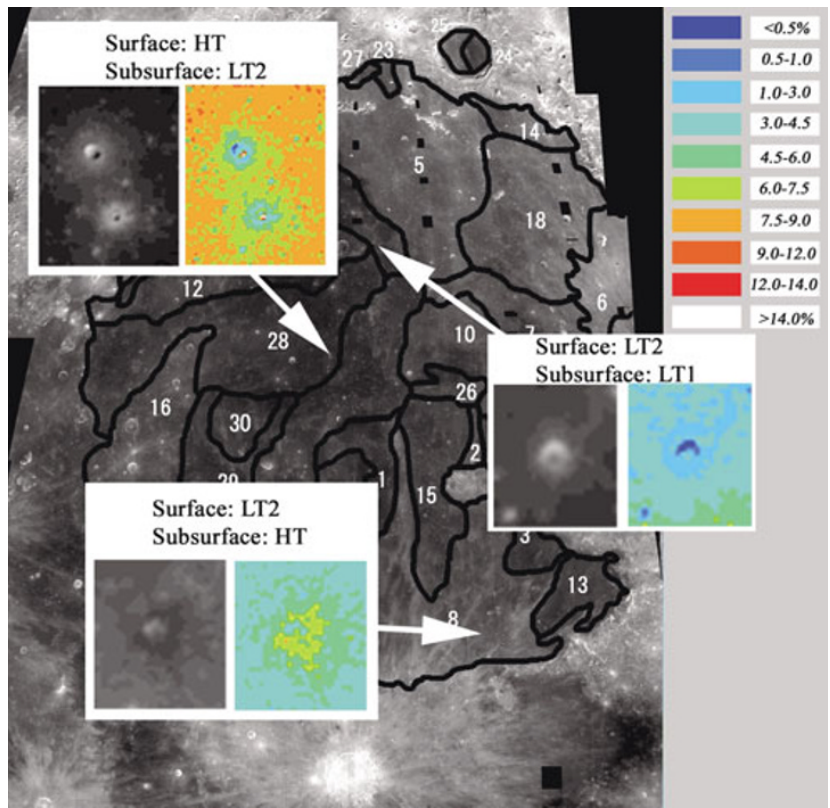

Fig. 8. Impact craters and ejecta distributed around the craters. These excavated materials have different $\mathrm{TiO}_{2}$ content from the surface material.

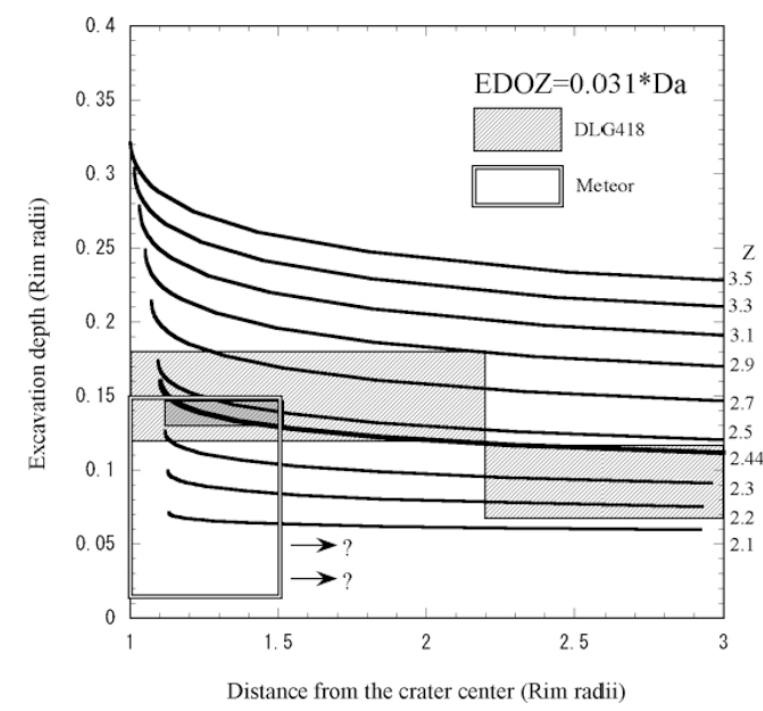

Fig. 9. Relations between the surface material of an ejecta blanket and its depth of origin based on laboratory experiments (Stöffler et al., 1975; DLG 418), the field study of Meteor Crater (Shoemaker, 1974), and model simulations using the Z-model and scaling law of ejection velocity. The upper range of Kaibab ejecta distribution may actually be larger than 1.5 radii since rocks of a younger age obscure the distribution limit of Kaibab ejecta. Overlapped area of the results is shown in gray; the surface of the ejecta blanket between 1.1 and 1.5 radii from the crater center is derived from a depth of $0.13-0.15$ radii. EDOZ is the depth of the effective center of Z-model flow (Fig. A.1).

ical examples of impact craters, ejecta distributed around the craters, and their $\mathrm{TiO}_{2}$ content. These excavated material have different $\mathrm{TiO}_{2}$ contents from the surface material, which is represented by the color code in the area far from the crater. This indicates that the chemistry of the area near the crater rim may represent that of the subsurface layer. The ejecta distribution of craters obtained in laboratory experiments, field studies, and simplified quantitative model are described below. 


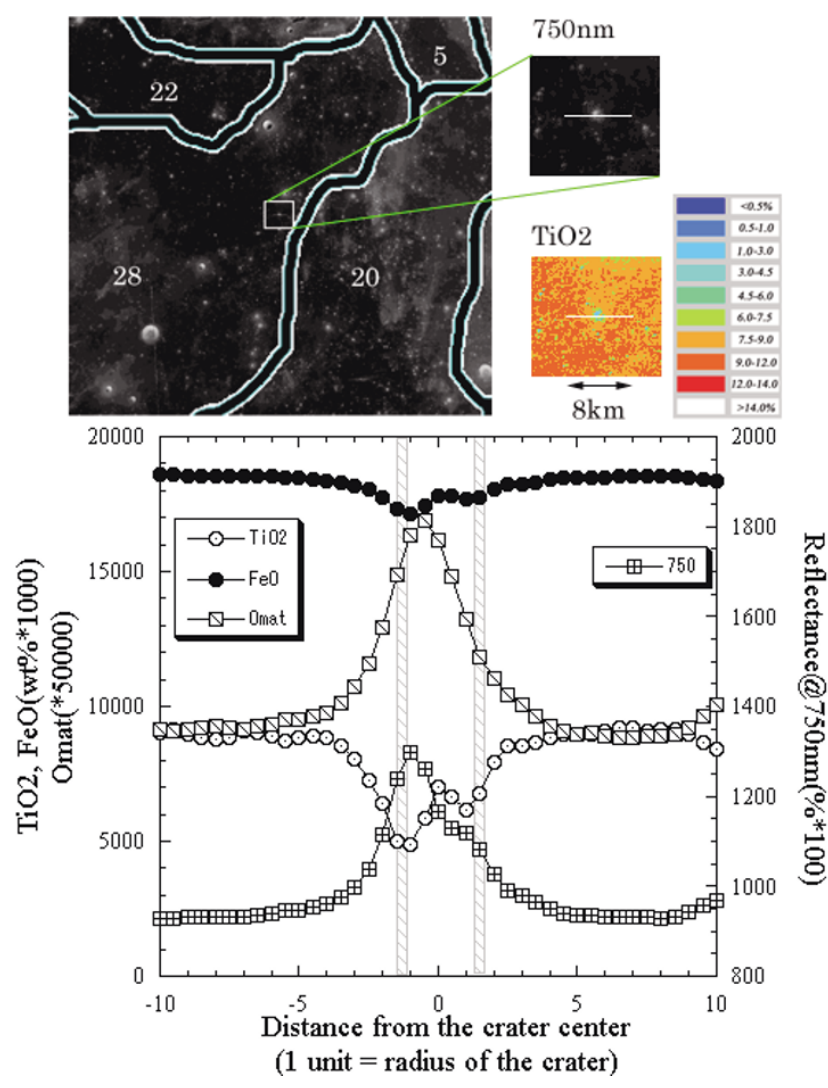

Fig. 10. $\mathrm{TiO}_{2}, \mathrm{FeO}$, Omat value, and reflectance at $750 \mathrm{~nm}$ of pixels on the traverse of a crater in Mare Imbrium. With distance away from the crater rim, $\mathrm{TiO}_{2}$ increases and reflectance and Omat decreases monotonically toward those of surrounding basalt, indicating that this crater excavated subsurface low-Ti basalt or highland material Using the method described in this paper, we determined $\mathrm{TiO}_{2}$ content of basalt shallower than $112 \mathrm{~m}$ to be $5.5 \mathrm{wt} \%$, which is an average content of the pixels between 1.1 to 1.5 crater radii from the crater center (hatched area).

Since all impact craters are surrounded by a deposit of debris from the crater interior, the composition of the ejecta blanket around the crater will provide information on the composition of subsurface material. A compilation of data in lunar craters by Moore et al. (1974) shows that the average radius of continuous ejecta, $\mathbf{R}_{c e}$, surrounding craters of radius $\mathrm{R}_{c r}$ is

$$
R_{c e}=(2.3 \pm 0.5) R_{c r}^{1.005}
$$

Although this relation is shown to be valid for lunar craters ranging from about 1.3 to $436 \mathrm{~km}$ in diameter, it also seems to hold for much smaller craters (Melosh, 1989). The spectral signature around a crater, as shown in Fig. 8, also suggests that the composition of the ejecta within the range up to $2 \mathrm{R}_{c r}$ in the studied craters $\left(\mathrm{R}_{c r}=0.2-3.0 \mathrm{~km}\right)$ is distinctly different from that in the range beyond $4 \mathrm{R}_{c r}$ and indicates that the craters are surrounded by ejecta materials whose chemistry represents the subsurface chemistry.

The original depth from which the ejecta blanket is excavated has been studied in various laboratory experiments, by field geology studies on terrestrial impact craters, and by theoretical simulation.

Stöffler et al. (1975) experimentally investigated the distribution of ejected material from hypervelocity impacts on loose silica sand. The crater shape and morphology of

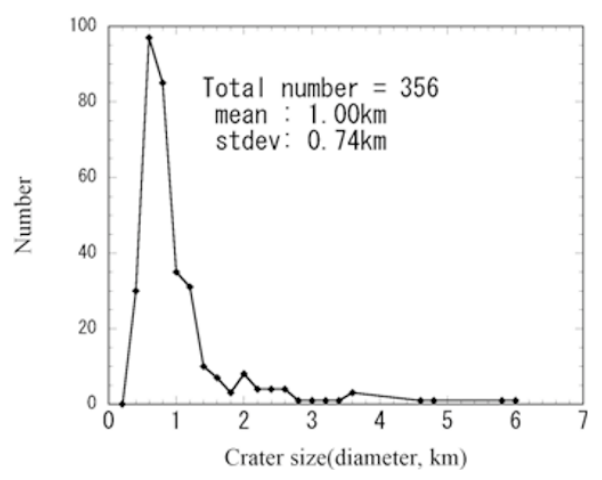

Fig. 11. Frequency of the crater size analyzed in this study.

ejecta blanket was found to be very similar to those commonly observed around terrestrial impact craters (Shoemaker, 1963). The area near the crater rim was covered by continuous ejecta. The surface of the area between the rim and 2.2 crater radius in radial distance was covered by a material which was originally placed at a depth of $0.12-$ 0.18 crater radius, and the area between 2.2 and 6.0 crater radii was covered by a material from the layer at a depth of $0.07-0.12$ crater radii.

Meteor Crater, a well-preserved impact crater in northern Arizona, has an average diameter of $1186 \mathrm{~m}$ (rim-torim) and in cross section has the form of a shallow bowl with an average depth of $167 \mathrm{~m}$ from rim crest to floor. The generalized stratigraphy and structure of the crater were described by Shoemaker (1974). Strata before the crater formation consists of Moenkopi $\left(0<d<0.014 R_{c r}\right)$, Kaibab $\left(0.014 R_{c r}<d<0.149 R_{c r}\right)$, Toroweap $\left(0.149 R_{c r}<d<\right.$ $\left.0.152 R_{c r}\right)$, Coconino $\left(0.152 R_{c r}<d<0.523 R_{c r}\right)$, and Supai $\left(0.523 R_{c r}<d<1.03 R_{c r}\right)$. The rim surface beyond the crest is underlain by an ejecta blanket composed of a sequence of inverted Coconino, Toroweap, Kaibab, and Moenkopi from top to bottom. The internal structure of the ejecta blanket consists mainly of blocky, fragmented beds that are continuous but lie in the same inverted stratigraphic order as seen on the rim surface. This overturned flap extends out to about three crater radii from the center of the crater, and volumetric calculations indicate approximately $0.7 \%$ of rock ejected from the crater was Moenkopi strata, $65.1 \%$ was Kaibab strata, and $34.2 \%$ was Coconino strata. Debris from the Kaibab layer $\left(0.014 R_{c r}<d<0.149 R_{c r}\right)$ covers the surface area between the rim and about 1.5 crater radii. However, the upper limit of the Kaibab ejecta distribution actually exceeds this since rocks of a younger age obscure the distribution limit of Kaibab ejecta.

Maxwell (1977) developed a simplified quantitative description of particle motion during the cratering flow stage for explosion craters (Z-model). Croft (1980) modified this model to describe both impact and explosion cratering flow fields. In the Z-model flow field streamline shapes are gravity-independent and geometrically similar in craters of all sizes, depending on the parameter $\mathrm{Z}$. Therefore, the maximum excavation depth of each streamline and the distance from the impact point where the streamline passes through the ground surface can be calculated. Ejection velocities are expressed with the scaling law by Housen et al. 


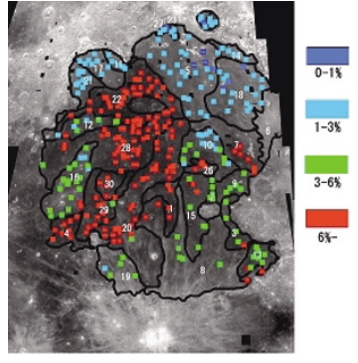

(a) surface

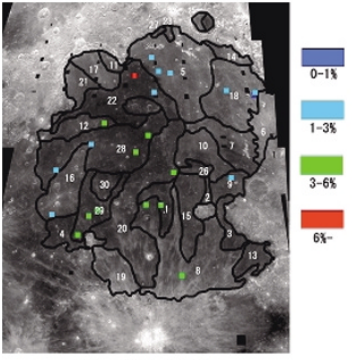

(d) $200-300 \mathrm{~m}$

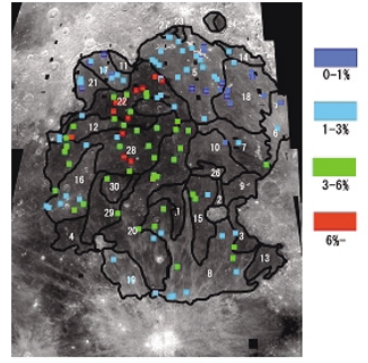

(b) $<100 \mathrm{~m}$

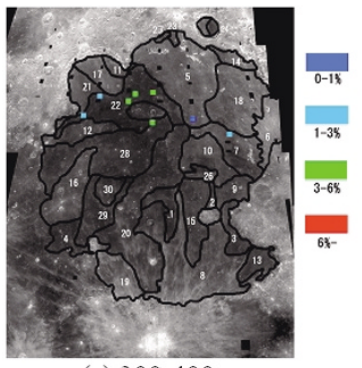

(e) $300-400 \mathrm{~m}$

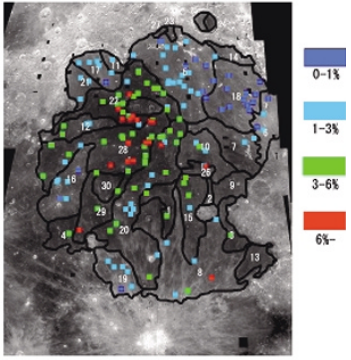

(c) $100-200 \mathrm{~m}$

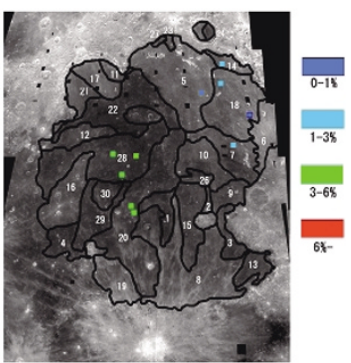

(f) $>400 \mathrm{~m}$

Fig. 12. Distribution of sampling data points in this study. Colors of the points displayed represent geologic types classified with $\mathrm{TiO}_{2}$ content.

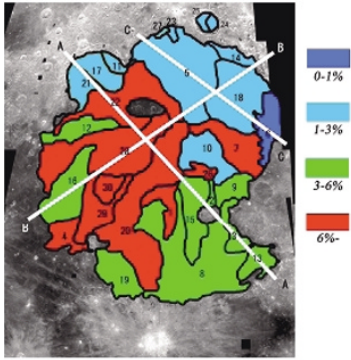

(a) surface

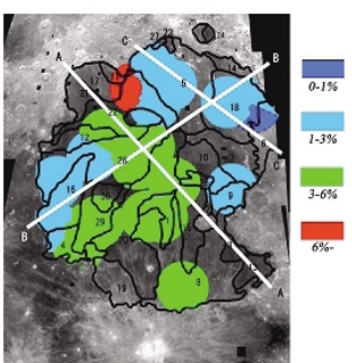

(d) $200-300 \mathrm{~m}$

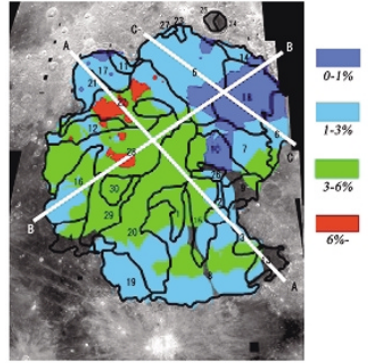

(b) $<100 \mathrm{~m}$

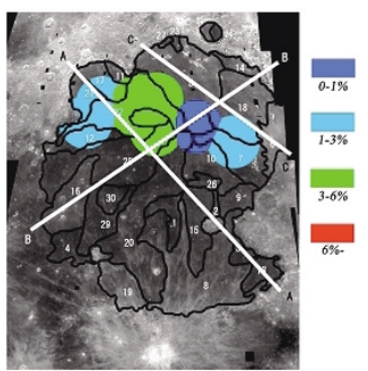

(e) $300-400 \mathrm{~m}$

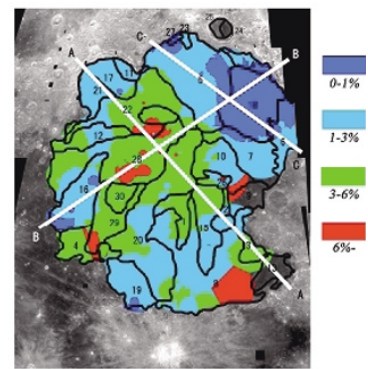

(c) $100-200 \mathrm{~m}$

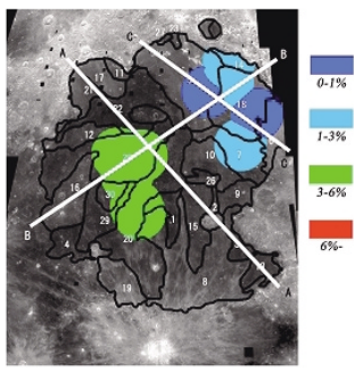

(f) $>400 \mathrm{~m}$

Fig. 13. Distribution of each geologic type on the surface and at each depth. Lines A, B and C shows cross-sections where compositional structures are estimated in Fig. 13

(1983) as a function of distance from the impact point. A model relating the surface material of an ejecta blanket and its depth of origin using the Z-model and the scaling law are described in detail in the Appendix. The relations for different $\mathrm{Z}$ parameters are compared with laboratory experimental and field observation data described in Fig. 9. The material ejected from a deeper subsurface layer is distributed nearer to the crater rim than material from a shallower layer for all values of $\mathrm{Z}$ in this figure, which is consistent with the ejecta distribution of DLG 418 in Stöffler et al. (1975). The maximum excavation of a crater is deeper for a larger parameter $Z$; as such, the excavation depth varies from 0.07 radii for $Z=2.1$ to 0.33 radii for $Z=3.5$. The distribution of ejecta for $\mathrm{Z}=2.44$ is in good agreement with the ejecta distribution of DLG 418 from depths between 0.07 and 0.12 , and between 0.12 and 0.18 radii. Ejecta between 1.0 and 1.5 radii from the center of Meteor Crater are derived from the Kaibab layer whose depth extends from 0.014 to 0.149 . However, the ejecta are excavated from a deeper part of this layer from the analogy of the results of DLG 418 experiments and Z-model calculation $(Z=2.44)$. The upper limit of Kaibab rock in ejecta is 1.5 radii based on the field study by Shoemaker (1974). The limit may actually be larger than this value (2.2 radii) since younger rocks obscure the distribution limit of Kaibab ejecta (Shoemaker, 1974) and by the analogy of the results of DLG 418 experiments and Z- 
model calculation $(\mathrm{Z}=2.44)$.

From the discussions in this section on the relations between ejecta distribution and depth of origin based on th e laboratory experiments, field study, and Z-model calculation, in this paper, we treat surface material of an ejecta blanket between 1.1 and 1.5 radii from the crater center as the ejecta from a depth of $0.13-0.15$ radii $(0.14$ radii on behalf of the range) (Fig. 9).

Moore et al. (1974) compiled data on lunar craters and found that the average radius of continuous ejecta surrounding craters is about 2.3-fold the crater radius with a diameter of $1.3-436 \mathrm{~km}$ and exceeds 2.3 -fold for smaller craters less than $1.3 \mathrm{~km}$ diameter. Therefore, the entire surface between 1.1 and 1.5 crater radii from the crater center is covered by the ejecta blanket, and few materials of the pre-impact surface are exposed in this area.

Figure 10 shows $\mathrm{TiO}_{2}$ and $\mathrm{FeO}$ contents, the Omat value, and reflectance at $750 \mathrm{~nm}$ of pixels on the traverse of a crater in Mare Imbrium. This crater, with a diameter of $800 \mathrm{~m}$ and a maximum excavation depth of $120 \mathrm{~m}$, is in a region where high-Ti basalt covered the lunar surface. As distance from the crater rim increases, $\mathrm{TiO}_{2}$ content increases and reflectance and Omat decrease monotonically toward values of the surrounding basalt, indicating that this crater excavated subsurface low-Ti basalt or highland material. In this example, spectral analysis identified the subsurface material as low-Ti basalt since it has strong absorption produced by iron-bearing minerals. Using the method described in this section, we determined the $\mathrm{TiO}_{2}$ content of basalt at a depth of $112 \mathrm{~m}$ to be $5.5 \mathrm{wt} \%$, which is an average content of the pixels between 1.1 to 1.5 crater radii from the crater center.

\section{Analysis and Results}

In order to study the subsurface composition, we selected 356 fresh craters on the basis of the Omat values of ejecta material (higher than 0.19) shown in Fig. 4. Although it is desirable to examine a variety of crater sizes to extract information of compositional layering, most of the selected craters are smaller than $2 \mathrm{~km}$ in diameter; therefore, subsurface structures deeper than $300 \mathrm{~m}$ cannot be inferred in this study. The diameter histogram of the selected crater is shown in Fig. 11. The average size of the craters chosen in this study was $1.0 \mathrm{~km}$ with a standard deviation of $0.74 \mathrm{~km}$.

For each crater, we determined $\mathrm{TiO}_{2}$ contents at a depth of 0.14 -fold greater than the crater radius in the preimpact subsurface structure by averaging of the pixels between 1.1 and 1.5 radii from the crater center as described in the preceding section. The $\mathrm{TiO}_{2}$ contents of the surface and subsurface (the ejecta around the craters) are shown in Fig. 12.

In order to derive the areal $\mathrm{TiO}_{2}$ distribution, we determined the $\mathrm{TiO}_{2}$ classification of each pixel using that of the discrete sampling data points in Fig. 12 as follows. First, we extracted all of the data points in Fig. 12 within 100 $\mathrm{km}$ of the pixel. Next, we summed up the reciprocal of the distance between the pixel and the extracted data points for each $\mathrm{TiO}_{2}$ classification (VLT, LT1, LT2, HT);

$\sum_{\text {Points } \in V L T} \frac{1}{r}, \quad \sum_{\text {Points } \in L T 1} \frac{1}{r}, \quad \sum_{\text {Points } \in L T 2} \frac{1}{r}, \quad \sum_{\text {Points } \in H T} \frac{1}{r}$

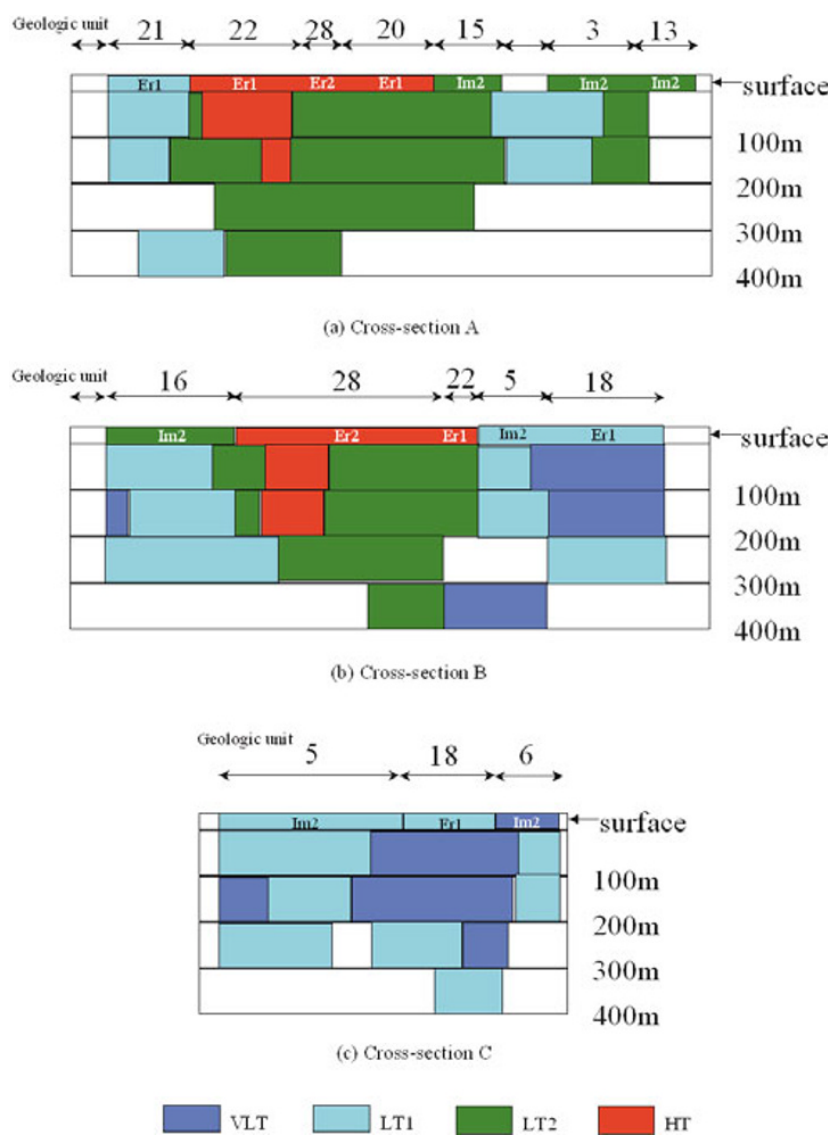

Fig. 14. Distribution of geologic types in cross-sections A, B and C.

Last, the $\mathrm{TiO}_{2}$ classification which serves as the maximum of the above four values was determined as the $\mathrm{TiO}_{2}$ classification of the pixel. Either the classification of the point whose distance from the pixel is near or the classification with many points will be chosen. If no data point existed within the distance of $100 \mathrm{~km}$ around the pixel, no classification was adopted as the $\mathrm{TiO}_{2}$ classification at the pixel. In this way, the $\mathrm{TiO}_{2}$ classification at all pixels was determined. The areal $\mathrm{TiO}_{2}$ distribution thus obtained is shown in Fig. 13, and three cross sections (A, B and C) in Fig. 13 are shown in Fig. 14.

As described previously and clearly shown in Fig. 13(a), the HT basalts dominate in the western part of the Mare Imbrium, whereas they significantly diminish in proportion in the subsurface basalts. This suggests that the most of the surface HT basalts are shallower than $100 \mathrm{~m}$ in thickness and certainly shallower than $300 \mathrm{~m}$. This conclusion indicates that the HT basalts constitute a very small portion of basalts in Mare Imbrium, where the basalts extend to a depth of 1000-1500 m (De Hon, 1979).

The surface areal fraction of LT2 and HT basalts are almost the same, while LT2 basalts are distributed to a larger extent and depth than HT basalts under the ground. The latter surround the HT basalts both horizontally and vertically (Figs. 13 and 14), and their maximum depth exceeds 400 $\mathrm{m}$, indicating that the volume of the LT2 basalts is much larger than that of HT basalts. Since the ages of surface LT2 and HT basalts in cross sections A and B are Im2 and Er1/Er2, respectively, volcanic activities in Mare Imbrium 
drastically decreased and $\mathrm{TiO}_{2}$ content changed from LT2 to $\mathrm{HT}$ around the transition of the Imbrian to Eratosthenian period.

The VLT and LT1 basalts are distributed in the outer region on the surface and at all depths (Fig. 13). As shown in Figs. 14(b) and (c), VLT and LT1 basalts erupted by turns during the $\operatorname{Im} 2$ and Er1 periods. As shown in Fig. 6, $45 \%$ of all LT1 basalts on the surface erupted during the Imbrian period. However, this ratio becomes larger when subsurface LT1 basalts are considered. For example, among the subsurface LT1 basalt shallower than $100 \mathrm{~m}$, two-thirds are overlaid by the $\operatorname{Im} 2$ basalts on the surface; therefore, at least two-thirds of basalts at this depth range erupted in or before the $\operatorname{Im} 2$ period. From these results, we conclude that the VLT and LT1 basalts erupted mainly during the $\operatorname{Im} 1$ or Im 2 period.

\section{Discussion}

A model on the genesis of mare basalt should satisfy the observed constraints described in the previous section. The model should incorporate (1) wide $\mathrm{TiO}_{2}$ variation $(0.5$ to $11 \mathrm{wt} \%)$, (2) long-duration volcanic activity (3.9-2.3 Ga), (3) $\mathrm{TiO}_{2}-\mathrm{FeO}$ correlation represented by a continuous trend curve, (4) a large volume of VLT/LT1/LT2 basalts mainly in the Imbrian period, and (5) small volume of HT basalts during the last stage of volcanic activity (Eratosthenian period) in Imbrium basin.

The wide variation of $\mathrm{TiO}_{2}$ in the basalts presented here argues for the existences beneath the Imbrium basin of the chemically differentiated shallow zone (Ti-rich) and the primitive lunar interior (Ti-poor) both of which have been interpreted to be separated during the lunar magma ocean process (e.g., Taylor and Jakes, 1974; Walker et al., 1975).
VLT,LT,LT2

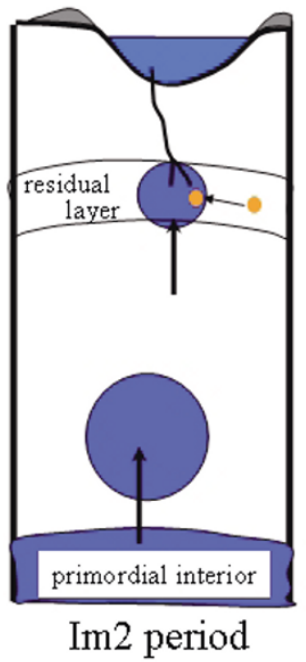

HT

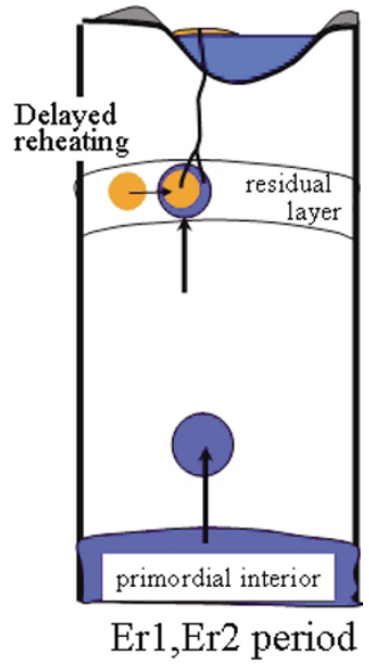

Fig. 15. Model showing magma genesis that explains the compositional change in mare basalt. (a) Im 2 period (VLT and LT basalts). Primitive basaltic magmas (blue in this figure) erupt onto the surface with a little assimilation by the Ti-rich residual magmas (orange). (b) Er1 and Er2 period (HT basalt). Extensive assimilations of the Ti-rich residual magma into the primitive magma occur due to the delayed reheating and remelting of materials in those regions, hundreds of million years after the impact.
The continuous correlation between $\mathrm{TiO}_{2}$ and $\mathrm{FeO}$ contents suggests that all types of basalt (VLT/LT1/LT2/HT) were produced by the hybridization of those two sources at various proportions. This single correlation also suggests a lateral homogeneity of the lunar mantle in the range of Imbrium basin.

The large volume of VLT/LT1/LT2 basalts that erupted during the Imbrian period implies that the deep, primordial interior should have been heated up so that partial melting occurred to a large extent in this period. Therefore, it provides further support for the model of Ringwood (1976) that the primitive region that is deeper than lunar magma ocean (LMO) continues to increase in temperature until it reaches the solidus owing to heating by its original $\mathrm{U}$, Th, and $\mathrm{K}$. Consequently, as shown in Fig. 15(a), zones of incipient melting thereby form and develop into a series of rising diapirs and erupt onto the surface as VLT and low-Ti basalts.

The drastically decreased eruption volume during the Eratosthenian period compared with those during the Imbrium period implies that the diapirs rising from the primitive region drastically decreased around the transition of the Imbrian to Eratosthenian period. It is suggested, on the other hand, that the increasing assimilation of the diapirs from the primitive interior by the chemically differentiated magma (Ti-rich) resulted in the change from the Imbrian VLT/LT1/LT2 to the Eratosthenian HT basalts.

The long duration of eruption over 1 billion years from the Imbrian to Eratosthenian period should have required another heat source in the chemically differentiated shallow zone during the Eratosthenian period. The impactassociated thermal model (Arkani-Hamed, 1974; Strangway and Sharpe, 1975) proposes that radiogenic heat from the deep undifferentiated interior is accumulated under the rims of giant impact craters where it has the maximum insulation effect of thick, low-thermal conductivity ejecta blankets. These researchers estimated that the heat is adequate to allow delayed reheating and remelting of materials in those regions hundreds of million years after the impacts. The time span and the shallow location of the HT basalt source deduced from our study may offer further evidence for their thermal model for remelting in the shallow subsurface zone.

Thus, it is plausible that under the Imbrium basin that the Ti-poor magmas were produced in the primitive interior under the Imbrium basin and that they were assimilated increasingly by the shallow Ti-rich magmas that melted due to the reheating hundreds of million years after the Imbrium basin formation. Both processes resulted in the variety of chemical composition, the change in eruption volume, and the long eruptive activity over 1 billion years in this basin.

The high-Ti basalts from the Apollo 11 and 17 landing sites are generally older (3.6-3.9 Ga) than the low-Ti basalts from the Apollo 12 and 15 sites and the VLT basalts from Mare Crisium (3.2-3.4 Ga) (Neal and Taylor, 1992). Based on this relationship between the age and chemistry of the returned lunar samples, several models have been developed to explain the source regions of mare basalts. Ringwood and Kesson (1976) proposed a "dynamic assimilation model" for mare basalt petrogenesis. In this model, pods (dimensions of the order of 5-20 km) of Fe, Ti-rich LMO 
residual liquid formed a thin global shell between the crust and the early cumulates. The large pods differentiated and segregations of ilmenite-rich pyroxenites proceeded more efficiently than the smaller pods. Following this, the dense ilmenite-pyroxenites became detached from the less-dense liquid and began to sink through the underlying early cumulates, most of which reached the primordial interior prior to $3.8 \mathrm{Ga}$. The penetration of the pods into partially molten primordial interior was accompanied by extensive partial melting of pods, producing hybrid magmas, and rising diapirs. Smaller, less-dense and less differentiated pods sank much more slowly than the large pods and entered the primordial mantle around $3.3 \mathrm{Ga}$. In this way, the high-Ti basalts should be older than the low-Ti and VLT basalts in their model, which is the reverse of our results revealing the trend of increasing Ti contents with time in Mare Imbrium. The dynamic assimilation model, therefore, cannot be applied under the Imbrium basin.

\section{Conclusions}

This study investigated the distribution of geologic units in Mare Imbrium. The compositional data of crater ejecta were used as an indicator to reveal subsurface distributions of the mare basalt. On the basis of these structures and comparing compositional data with crater-counting ages for the mare basalt on the surface, the compositional variation with time reveals that the averages of $\mathrm{TiO}_{2}$ and $\mathrm{FeO}$ content increase with time from the Imbrian to the Eratosthenian periods, which is represented by a continuous curve on the $\mathrm{TiO}_{2}-\mathrm{FeO}$ graph (Fig. 7). Also, the volume of basalts erupting during the Eratosthenian period was shown to have decreased drastically compared with the basalt volume erupting during the Imbrian period.

The model in which primitive magma generated in the undifferentiated interior is assimilated by the residual Tirich magma, which remelts more extensively hundreds of million years after the basin formation, explains the variation in chemical composition and the change of eruption volume with time, and the long period of volcanic activity.

Since the thermal structure inside the Moon has evolved with time, the composition and volume of mare basalts are expected to depend on the time when a basin was formed by a giant impact. In order to verify the model of the mare basalt generation described in this paper, we are going to investigate the detailed surface and subsurface distribution of other maria using the method reported in this paper and compare them with the time of the basin formation.

The lunar explorer SELENE (SELenological and ENgineering Explorer), will be launched in summer of 2007. Multi-band Imager, Spectral Profiler, X-ray Spectrometer, and Gamma-ray Spectrometer will identify mineral and elemental compositions with a high spatial and spectral resolution. Lunar Radar Sounder will investigate the underground structure. The data obtained by these instruments will also be important for our study.

Acknowledgments. The authors thank Dr. Patrick Pinet and an anonymous reviewer for constructive and thoughtful comments. We also wish to thank the staff of SELENE project team for many useful discussions and for their review of the present work.

\section{Appendix A. A Mathematical Description of Ejecta Distribution using Z-model and the Scaling Law of Ejection Velocity}

In this appendix, quantitative formulae are derived for relating the ejecta distribution and its depth of origin. Figure A.1 defines the geometry and symbols for the flow field used in this study. Austin et al. (1980) indicated that $Z$ and $\alpha$ are approximately constant for EDOZ equivalent to 0.031 apparent crater diameters while the crater grows from twothirds to its nearly final dimensions. We calculated the volume ratio of materials originating from each underground layer, and the ejection angle and velocity are calculated for a streamline pass through the ground surface at distance $x$ from the impact point. The radial and angular components of the flow velocity at distance $R$ from EDOZ along a streamline are:

$$
\begin{aligned}
& u_{r}=\alpha R^{-Z} \\
& u_{\theta}=u_{r}(Z-2) \sin \theta /(1+\cos \theta)
\end{aligned}
$$

where $Z$ is the dimensionless power and $\alpha$ is a function of time giving the flow strength. The equation of a streamline in polar coordinates is:

$$
\begin{aligned}
R & =R_{0}(1-\cos \theta)^{1 /(Z-2)} \\
R_{0} & =\frac{x}{\cos \Delta(1+\sin \Delta)^{1 /(Z-2)}} \\
\tan \Delta & =\frac{d}{x}
\end{aligned}
$$

where $R_{0}$ is a constant that differs for each streamline and equals the radius at which the streamline passes through the same level of EDOZ (depth $d$ ). The ejecta from layer $k$ along the streamlines between $R_{0}$ and $R_{0}+\Delta R_{0}$ originate from the area shown in Fig. A.1 (gray area). For axial symmetry and (A.3) relating $R$ and $\theta$, the volume of rotation of the area in Fig. A.1 is given by:

$$
\begin{aligned}
V_{\theta 1 \_}{ }_{\theta 2}= & \iiint R^{2} \sin \theta d R d \theta d \psi \\
= & 2 \pi \iint R^{2} \sin \theta d R d \theta \\
= & 2 \pi \int_{\theta_{1}}^{\theta_{2}} \int_{R_{0}}^{R_{0}+\Delta R_{0}} R^{\prime 2}(1-\cos \theta)^{3 /(Z-2)} \\
= & 2 \pi R_{0}^{2} \Delta R_{0}\left(\frac{Z-2}{Z+1}\right) \\
& \times\left[\left(1-\cos \theta_{2}\right)^{(Z+1) /(Z-2)} d R^{\prime} d \theta\right. \\
& \left.\quad-\left(1-\cos \theta_{1}\right)^{(Z+1) /(Z-2)}\right]
\end{aligned}
$$

where $\theta_{1}$ and $\theta_{2}$ are the angular components of intersections between the streamline and top and bottom of the layer $k$, respectively.

The ejection angle of the streamline at distance from the impact point is given by equation 1f in Croft (1980):

$$
\phi=\tan ^{-1}\left[\frac{\frac{\tan \Delta}{\cos \Delta}-\tan ^{2} \Delta+(Z-2)}{\frac{1}{\cos \Delta}-\tan \Delta \cdot(Z-1)}\right]
$$




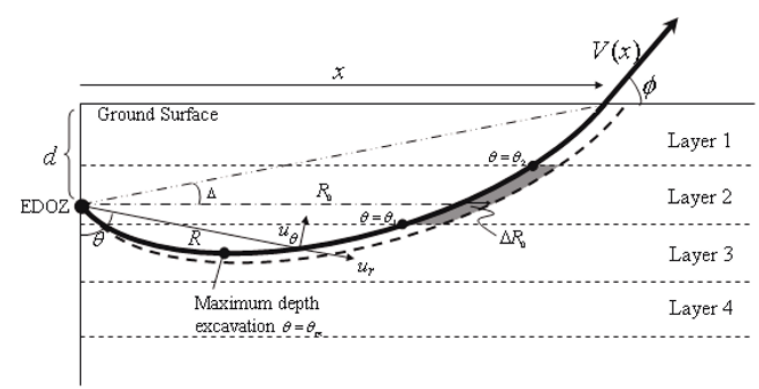

Fig. A.1. Geometry and symbols for the Z-model flow field used in this study. Volume of rotation of the gray area was calculated to determine the ejecta volume from the underground layer.

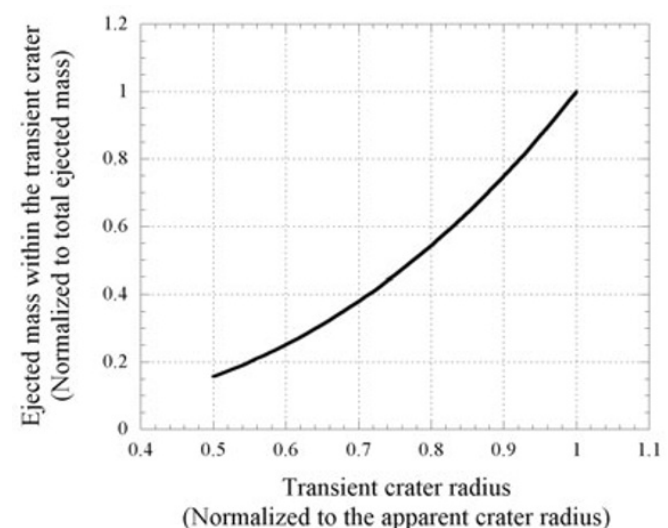

Fig. A.2. Ejected volume within the transient crater (at the time of ejection at $x^{*}$ ), which is given by equation $3 \mathrm{e}$ in Croft (1980). The radii of transient craters having ejected $38 \%, 54 \%$ and $75 \%$ of the total ejecta mass are $x^{*}=0.7,0.8$, and 0.9 .

Substitution of (A.3) into (A.2) and $\theta=90+\Delta$ at the ground surface yields the ejection velocity:

$$
\begin{aligned}
V(x)= & \sqrt{u_{r}{ }^{2}+u_{\theta}{ }^{2}} \\
= & \alpha{R_{0}}^{-Z}(1+\sin \Delta)^{-Z /(Z-2)} \\
& \times\left[1+(Z-2)^{2} \frac{\cos ^{2} \Delta}{(1-\sin \Delta)^{2}}\right]^{1 / 2}
\end{aligned}
$$

Specific expressions of scaling laws for ejection velocities have been presented in both gravity and strength regimes by Housen et al. (1983). This paper considers only the gravity regime since the diameters of craters analyzed exceed $400 \mathrm{~m}$ where the transition between strength and gravity regimes should occur on the Moon (Melosh, 1989). The ejection velocity at distance $x$ from the impact point in the gravity regime is expressed as:

$$
\frac{V(x)}{\sqrt{g R_{a}}}=K_{1}\left(\frac{x}{R_{a}}\right)^{-\gamma}
$$

where $R_{a}$ is the apparent crater radius and $K_{1}$ and $\gamma$ are constant values. Piekutowski (1980) measured ejecta velocities as a function of launch position for a tangent-below explosion in dry Ottawa sand, and Housen et al. (1983) found $K_{1}$ and $\gamma$ to be 0.62 and -2.55 . Oberbeck and Morrison (1976)

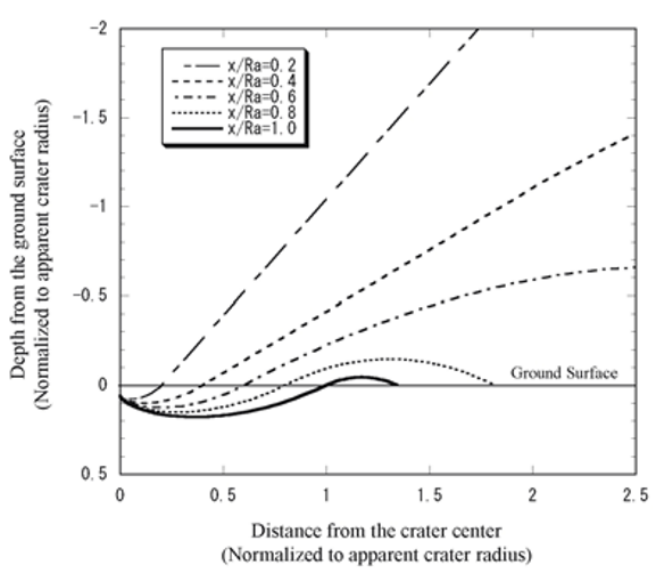

Fig. A.3. Streamlines determined by $\mathrm{Z}$-model $(\mathrm{Z}=2.44$ and $\mathrm{EDOZ}=0.031$ apparent crater diameter) and ballistic trajectories for which initial ejection velocity is expressed as (A.17). The velocities of ejecta launched at $=0.2$ or 0.4 are so large that these ejecta are distributed beyond 20 apparent crater radii.

measured $V(x)$ for small-scale impacts into sand targets. Their experiment results differed from those of comparable experiments (Stöffler et al., 1975; Piekutowski, 1980) in that $V(x)$ decreased linearly with $x$, in contrast to the power-law behavior in (A.9) and the highest velocities are one to two orders of magnitude lower. The presence of the dissector plate, which breaks the ejecta plume into discrete packets of ejecta, seems to have affected the appearance of the ejecta plume (Housen et al., 1983).

Therefore, we use $K_{1}$ and $\gamma$ factors for impact cratering ejecta from other experimental results. Using the powerlaw coefficients between crater volume and gravity-scaled size in Schmidt (1980), Housen et al. (1983) calculated $\gamma$ to be 2.44 for impact cratering in Ottawa sand (see Table 2 in their paper). Substituting (A.4) and (A.5) into (A.8) and expressing $V(x)$ as a power-law function of $x / R_{a}$ gives:

$$
Z \approx \gamma=2.44
$$

The range $r_{1}$ referenced to the impact point is the sum of the ballistic range and position of ejection within the crater, $x$. We define $v_{f}$ as the minimum ejection velocity near the terminal stage of crater growth:

$$
v_{f}=V\left(x=R_{a}\right)=K_{1} \sqrt{g R_{a}}
$$

For notational convenience, we define $r_{1}{ }^{*}=r_{1} / R_{a}, x^{*}=$ $x / R_{a}, v^{*}=V(x) / \sqrt{g R_{a}}$, and $v_{f}{ }^{*}=v_{f} / \sqrt{g R_{a}}$. The ballistic equation for a flat surface is:

$$
r_{1}^{*}=x^{*}+v^{* 2} \sin (2 \phi)
$$

Substituting (A.9) and (A.11) into (A.12) gives:

$$
\begin{array}{r}
r_{1}{ }^{*}=x^{*}+v_{f}{ }^{* 2} x^{*-2 \gamma} \sin (2 \phi) \\
x^{*-1}\left[r_{1}{ }^{*}-v_{f}{ }^{* 2} x^{*-2 \gamma} \sin (2 \phi)\right]=1
\end{array}
$$

Since $0<x^{*}<1$, upper and lower bounds for the second term of (A.13) are:

$$
\begin{array}{r}
0<r_{1}{ }^{*}-v_{f}{ }^{* 2} x^{*-2 \gamma} \sin (2 \phi)<1 \\
\sqrt{\left(r_{1}{ }^{*}-1\right)}<x^{*-\gamma} v_{f}{ }^{*} \sqrt{\sin (2 \phi)}<\sqrt{r_{1}{ }^{*}}
\end{array}
$$




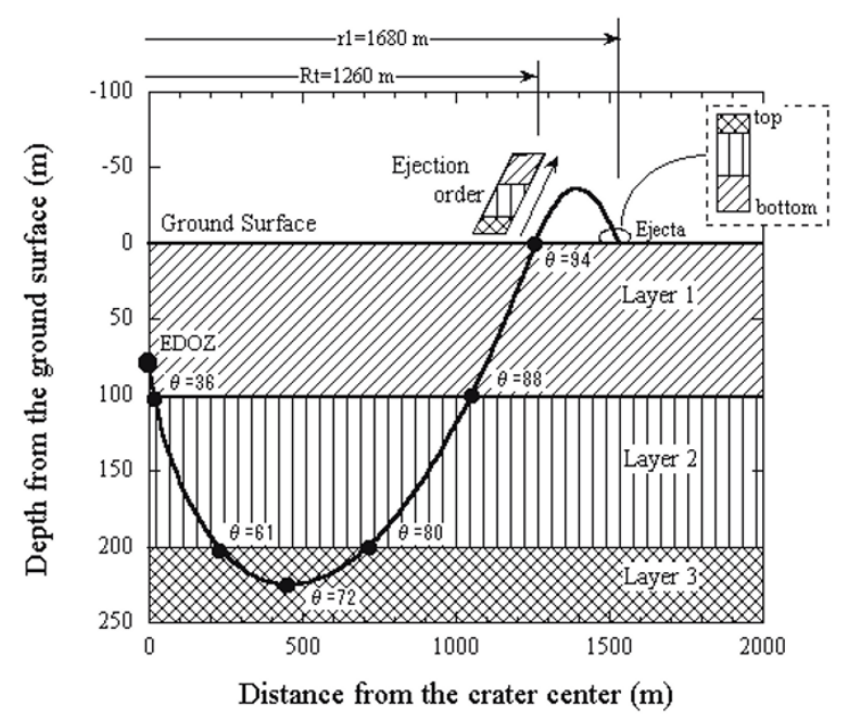

Fig. A.4. Trajectory ejected at a distance of $1260 \mathrm{~m}$ from the center of a crater with an apparent radius of $1260 \mathrm{~m}(=1.0)$. Z-model flow begins at a depth of $78 \mathrm{~m}$ below the impact point; crosses the layer boundaries at $\theta=36,61,80$, and 88 degrees; exits at $1260 \mathrm{~m}$ and $\theta=94$ degrees; and deposits ejecta at $1680 \mathrm{~m}$, which is just outside the crater rim (1530 $\mathrm{m})$. The maximum excavation occurs at $\theta=72$ degrees for $\mathrm{Z}=2.44$. The ejection occurs with a sequence of layers along the streamline. However, the volume of material along the streamline with $\theta<72$ is negligible. Therefore, ejecta are accumulated with a sequence of strata inverted from the pre-impact sequence, which is consistent with the results of laboratory experiments (ex. Stöffler et al., 1975).

In order to relate $r_{1}{ }^{*}$ and $x^{*}$, we used the ejecta distribution of impact craters in the laboratory (Fig. 8 of Stöffler et al. (1975); $R_{a}=0.138 \mathrm{~m}$, using the relation by Melosh (1989) that $R_{a}$ equals 0.84 crater rim radii), which yields approximately $38 \%, 54 \%$ and $75 \%$ of the total ejecta mass beyond $r_{1}{ }^{*}=2.5,1.8$, and 1.2 from the point of impact, respectively. Ejected volume within the transient crater (at the time of ejection at $x$ ) is shown in Fig. A.2, which is given by the following equation from equation. 3 e in Croft (1980):

$$
V_{\text {ejected }}(x)=\left[\frac{\pi}{3} \cdot \frac{d}{x}+\frac{2 \pi(Z-2)}{3(Z+1)} \cdot \frac{1+\sin \Delta}{\cos ^{3} \Delta}\right] x^{3}
$$

From Fig. A.2, the radii of transient craters that ejected $38 \%, 54 \%$ and $75 \%$ of the total ejecta mass are $x^{*}=0.7$, 0.8 , and 0.9 , respectively. Using the combinations of $\left(r_{1}{ }^{*}, x^{*}\right)=(2.5,0.7),(1.8,0.8)$ and $(1.2,0.9)$, and substituting (A.5), (A.7) and (A.10) into (A.14) gives:

$$
\left\{\begin{array}{l}
\sqrt{2.5-1}<0.7^{-2.44} v_{f}^{*} \sqrt{\sin (2 \times 30.7)}<\sqrt{2.5} \\
\sqrt{1.8-1}<0.8^{-2.44} v_{f}^{*} \sqrt{\sin (2 \times 29.9)}<\sqrt{1.8} \\
\sqrt{1.2-1}<0.9^{-2.44} v_{f} * \sqrt{\sin (2 \times 29.2)}<\sqrt{1.2}
\end{array}\right.
$$

$$
0.558<v_{f}^{*}=K_{1}<0.707
$$

In this paper, we use the middle value of this range; $v_{f}{ }^{*}=0.63$, and (A.9) for impact cratering in Ottawa sand is expressed as

$$
\frac{V(x)}{\sqrt{g R_{a}}}=0.63\left(\frac{x}{R_{a}}\right)^{-2.44}
$$

This nearly equals the equation for an explosion crater in the same type of material (Piekutowski, 1980; Housen et al., 1983).

The streamlines and ballistic trajectories are shown in Fig. A.3 using (A.3), (A.4), (A.5), and (A.17). The velocities of ejecta launched at $x^{*}=0.2$ or 0.4 are so large that these ejecta are distributed beyond 20 apparent crater radii. We can obtain the volume of excavated material from each underground layer at arbitrary points outside the crater using expressions (A.6) and (A.17). Figure A.4 shows the trajectory of material ejected $1260 \mathrm{~m}$ from the center of a crater with an apparent radius of $1260 \mathrm{~m}\left(x^{*}=1.0\right)$, which corresponds to the center-to-rim radius of $1500 \mathrm{~m}$. The thickness of each layer is taken to be $100 \mathrm{~m}$ in this paper. Z-model flow begins at a depth of $78 \mathrm{~m}$ below the impact point; crosses the layer boundaries at $\theta=36,61,80$, and $88^{\circ}$, exits at $x=1260 \mathrm{~m}$ and $\theta=94^{\circ}$; and deposits ejecta at a distance of $1680 \mathrm{~m}$, which is just outside the crater rim. The maximum excavation occurs at $\theta=\theta_{m}$, where $\theta_{m}=\cos ^{-1}[(Z-2) /(Z-1)]$ (see equation. 1e of Croft (1980)), and $\theta_{m}$ equals $72^{\circ}$ for $Z=2.44$. The ejection occurs with a sequence of layers along the streamline. However, the volume of material along the streamline with $\theta<\theta_{m}$ is negligible since the term of $(1-\cos \theta)^{(Z+1) /(Z-2)}$ in (A.6) is nearly constant at zero as shown. Therefore, ejecta are accumulated with a strata sequence inverted from the pre-impact sequence, which is consistent with the results of laboratory experiments (ex. Stöffler et al., 1975).

\section{References}

Arkani-Hamed, J., Effect of a giant impact on the thermal evolution of the moon, The Moon, 9, 183-209, 1974.

Austin, M. G., J. M. Thomsen, S. F. Ruhl, D. L. Orphal, and P. H. Schultz, Calculational investigation of impact cratering dynamics: Material motions during the crater growth period, Proc. Lunar Sci. Conf., 11, 23252345, 1980 .

Binder, A. B., The mare basalt magma source region and mare basalt magma genesis, J. Geophys. Res., 87, A37-A53, 1982.

Boyce, J. M., Ages of flow units in the lunar nearside maria based on Lunar Orbiter IV photographs, Proc. Lunar Sci. Conf., 7, 2717-2728, 1976.

Boyce, J. M. and A. L. Dial, Relative ages of flow units in Mare Imbrium and Sinus Iridum, Proc. Lunar Sci. Conf., 6, 2585-2595, 1975.

Croft, S. K., Cratering flow fields: Implications for the excavation and transient expansion stages of crater formation, Proc. Lunar Planet. Sci. Conf., 11, 2347-2378, 1980.

De Hon, R. A., Thickness of the western mare basalts, Proc. Lunar Planet. Sci. Conf., 10, 2935-2955, 1979.

Eliason, E. M., et al., Digital processing for a global multispectral map of the Moon from Clementine UVVIS imaging instrument, Lunar Planet. Sci., 30, 1933, 1999.

Green, D. H. and A. E. Ringwood, Significance of a primitive lunar basaltic composition present in Apollo 15 soils and breccias, Earth Planet. Sci. Lett, 19, 1-8, 1973.

Head, J. W., Mode of occurrence and style of emplacement of lunar mare deposits, Origins of Mare Basalts, 61-65, 1975.

Head, J. W. and L. Wilson, Lunar mare volcanism: Stratigraphy, eruption conditions, and the evolution of secondary crusts, Geochim. Cosmochim. Acta, 56, 2155-2175, 1992.

Hiesinger, H., J. W. Head, U. Wolf, and G. Neukum, Lunar mare basalts in Oceanus Procellarum: Initial results on age and composition, Lunar Planet. Sci., 31, 1278, 2000a. 
Hiesinger, H., R. Jaumann, G. Neukum, and J. W. Head, Age of mare basalts on the lunar nearside, J. Geophys. Res., 105, 29,239-29,275, $2000 \mathrm{~b}$

Hiesinger, H., J. W. Head, U. Wolf, and G. Neukum, Lunar mare basalts: Mineralogical variations with time, Lunar Planet. Sci., 32, 1826, 2001.

Housen, K. R., R. M. Schmidt, and K. A. Holsapple, Crater ejecta scaling laws: Fundamental forms based on dimensional analysis, J. Geophys. Res., 88, 2485-2499, 1983.

Hubbard, N. J. and J. W. Minear, A physical and chemical model of early lunar history, Proc. Lunar Sci. Conf., 6, 1057-1085, 1975.

Kesson, S. E., Mare basalts: Melting experiments and petrogenetic interpretations, Proc. Lunar Sci. Conf., 6, 921-941, 1975.

Lawrence, D. J., et al., Thorium abundances on the lunar surface, J. Geophys. Res., 105, 20,307-20,331, 2000.

Lucey, P. G., D. T. Blewett, and B. L. Jolliff, Lunar iron and titanium abundance algorithms based on final processing of Clementine ultravioletvisible images, J. Geophys. Res., 105, 20,297-20,305, 2000a.

Lucey, P. G., D. T. Blewett, G. J. Taylor, and B. R. Hawke, Imaging of Lunar surface maturity, J. Geophys. Res., 105, 20,297-20,305, 2000b.

Maxwell, D. E., Simple Z model of cratering, ejection, and overturned flap, in Impact and Explosion Cratering, p. 1003-1008, Pergamon, NewYork, 1977.

Melosh, H. J., Impact Cratering, Oxford University Press, NewYork, 1989.

Moore, H. J., C. A. Hodges, and D. H. Scott, Multiringed basins-illustrated by Orientale and associated features, Proc. Lunar Sci. Conf., 5, 71-100, 1974.

Neal, C. R. and L. A. Taylor, Petrogenesis of mare basalts: A record of lunar volcanism, Geochim. Cosmochim. Acta, 56, 2177-2211, 1992.

Nozette, S. and the Clementine team, The Clementine mission to the Moon: Scientific overview, Science, 266, 1835-1839, 1994.

Oberbeck, V. R. and R. H. Morrison, Candidate areas for in situ ancient lunar materials, Proc. Lunar Sci. Conf., 7, 2983-3005, 1976.

O'Hara, M. J., D. J. Humphries, and S. Waterston, Petrogenesis of mare basalts: Implications for chemical, mineralogical, and thermal models for the Moon, Proc. Lunar Sci. Conf., 6, 1043-1055, 1975.

Piekutowski, A. J., Formation of bowl-shaped craters, Proc. Lunar Sci.
Conf., 11, 2129-2144, 1980.

Ringwood, A. E., Some aspects of the miner element chemistry of lunar mare basalts, The Moon, 12, 127-157, 1975.

Ringwood, A. E. and S. E. Kesson, A dynamic model for mare basalt petrogenesis, Proc. Lunar Sci. Conf., 7, 1697-1722, 1976.

Sasaki, S., K. Nakamura, Y. Hamabe, E. Kurahasho, and T. Hiroi, Producution of iron nanoparticles by laser irradiation in a simulation of lunar-like space weathering, Nature, 410, 555-557, 2001.

Schaber, G. G., Lava flows in Mare Imbrium: Geologic evaluation from Apollo orbital photography, Proc. Lunar Sci. Conf., 4, 73-92, 1973.

Schmidt, R. M., Meteor crater: Energy of formation-implications of centrifuge scaling, Proc. Lunar Sci. Conf., 11, 2099-2128, 1980.

Shoemaker, E. M., Impact mechanics at Meteor Crater, Arizona, in The Solar System, edited by G. Kuiper, pp. 301-336, University of Chicago Press, Chicago, 1963.

Shoemaker, E. M., Synopsis of the geology of Meteor Crater, in Guidebook to the Geology of Meteor Crater, p. 1-11, 37 Ann. Mtg. Meteoritic Soc., Aug. 1974.

Shih, C. and E. Schonfeld, Mare basalt genesis: A cumulate-remelting model, Proc. Lunar Sci. Conf., 7, 1757-1792, 1976.

Stöffler, D., D. E. Gault, J. Wedekind, and G. Polokowski, Experimental hypervelocity impact into quartz sand: Distribution and shock metamorphism of ejecta, J. Geophys. Res., 80, 4062-4077, 1975.

Strangway, D. W. and H. N. Sharpe, A model of lunar evolution, The Moon, 12, 369-397, 1975.

Taylor, S. R. and P. Jakes, The geochemical evolution of the moon, Proc. Lunar Sci. Conf., 5, 1287-1305, 1974.

Walker, D., J. Longhi, E. M. Stolper, T. L. Grove, and J. F. Hays, Origin of titaniferous lunar basalts, Geochim. Cosmochim. Acta, 39, 1219-1235, 1975.

Wilhelms, D. E., The Geologic history of the Moon, U.S. Geol. Surv. Prof. Pap., 1348, 302pp, 1987.

H. Otake (e-mail: Ootake.Hisashi@jaxa.jp) and H. Mizutani 